\title{
Optimal Cross-Sectional Shape of Gas/Air Ducts
}

\section{Yongjian Gu}

Department of Marine Engineering United States Merchant Marine Academy Kings Point, New York, USA

Email: guy@usmma.edu

How to cite this paper: Gu, Y.J. (2016) Optimal Cross-Sectional Shape of Gas/Air Ducts. World Journal of Engineering and Technology, 4, 250-255.

http://dx.doi.org/10.4236/wjet.2016.43D030

Received: September 24, 2016

Accepted: October 22, 2016

Published: October 29, 2016

\begin{abstract}
In industrial plants, ships, and buildings, a large amount of gas and air ducts are applied for equipment connection, HVAC, medium transport, and exhaust, etc. These ducts can be designed in varied cross-sectional shapes, such as round or rectangle. The author reveals through geometric calculation of the duct cross-sectional shapes and engineering experiences that the round cross-section is an optimal shape in the duct system. The round duct has the shorter perimeter than the other cross-sectional shape ducts and the stronger structure in the same working condition. The material saving of the round duct due to the shorter perimeter is quantitatively determined. In the pater, it is shown that the round duct is economically attractive. The economic analysis for the material cost saving is illustrated by an example. For a long duct system, the material and material cost savings are significant. It is suggested that the round duct in the gas and air duct system should have priority as long as the field conditions are allowed. In the paper, the material cost saving is also converted to PW, AW, and FW used for LCC economic analysis.
\end{abstract}

\section{Keywords}

Optimal, Ducts, Cross-Sectional Shape, Economic and Cost Analysis

\section{Introduction}

Gas and air duct systems are widely applied in industrial plants, ships, and buildings for the purposes of equipment connection and medium transport, such as in HVAC and exhaust systems. The cross-sectional shapes of the ducts are frequently designed and built in rectangle, square, or round. The duct material most commonly is galvanized metal sheet. Insulations are used which depend on the duct application purposes. From a geometric view, the round duct has the least perimeter compared to the rectangular and square ducts with the equal flow sectional area. Therefore, the material of the round duct comparing to the square or rectangle duct with the equal flow sectional area 
can be reduced. While with the equal perimeters, the round duct has the greatest flow sectional area, which will reduce the flow friction apparently. Nevertheless, the round duct should be an optimal design in the ductwork application. The perimeter and cross-sectional area relations of these ducts are shown in Table 1. If a duct system has thousands feet long, the material saving and material cost saving will be significant and other benefits can be obtained by using the round duct.

\section{Material Saving and Benefits Using Round Duct}

In ductwork system design, the duct cross-sectional shape can be either round or rectangle with the same flow friction which means the equal flow sectional area. The equation relating diameter $\mathrm{D}$ of the round duct and side lengths of the rectangular duct will be [1]

$$
D=\frac{1.3 \mathrm{a}(b / a)^{\frac{5}{8}}}{(1+b / a)^{\frac{1}{4}}}
$$

After a few manipulations, Equation (1) can be expressed as

$$
D=\frac{1.3(a b)^{\frac{5}{8}}}{(a+b)^{\frac{1}{4}}}
$$

Then $k$, a perimeter ratio of the round duct to the rectangular duct, is

$$
k=\frac{\pi \mathrm{D}}{2(\mathrm{a}+\mathrm{b})}=\frac{1.3 \pi(\mathrm{a} b)^{\frac{5}{8}}}{2(\mathrm{a}+\mathrm{b})(\mathrm{a}+\mathrm{b})^{\frac{1}{4}}}
$$

Equation (3) becomes after rearrangement

$$
k=0.65 \pi \sqrt[8]{\frac{R^{5}}{(1+R)^{10}}}
$$

where $R=a / b=$ long-side length/short-side length

From the manufacturing consideration, $R$ shall be kept below 8 . The results of perimeter ratio $k$ varies with aspect ratio $R$ and description are listed in Table 2.

It can be seen that less perimeter needs for the round duct comparing to the rectangular duct. The larger $R$ is, the less $k$ has, which means less material for the round duct than that for the rectangular duct. From the practice of industry, $R$ value usually is

Table 1. Perimeter and area relations.

\begin{tabular}{lcc}
\hline & Shape & Equal Areas \\
\hline Rectangle & Has the least area & Has the greatest perimeter \\
Square & Has a greater area than rectangle & Has a perimeter less than rectangle \\
Round & Has the greatest area & Has the least perimeter \\
\hline
\end{tabular}


Table 2. Variance of $K$ with $R$.

\begin{tabular}{ccc}
\hline$R$ Value & $k$ Value & Perimeter of a round duct is \\
\hline 1 & 0.86 & $85 \%$ a rectangular duct \\
2 & 0.80 & $80 \%$ a rectangular duct \\
3 & 0.72 & $72 \%$ a rectangular duct \\
4 & 0.65 & $65 \%$ a rectangular duct \\
5 & 0.60 & $60 \%$ a rectangular duct \\
6 & 0.55 & $55 \%$ a rectangular duct \\
7 & 0.51 & $51 \%$ a rectangular duct \\
8 & 0.48 & $48 \%$ a rectangular duct \\
\hline
\end{tabular}

kept around 2. The duct material, therefore, can be save $20 \%$ by using the round duct. In other words, the material cost saving is $20 \%$ for the round duct comparing to the rectangular duct.

1) Metal Sheet Material Cost Saving

Galvanized metal steel is the most common material used in ductwork fabrication. Cost for fabricating ductworks is usually based on the total mass of the duct and fittings. For a straight duct with galvanized metal steel, the unit price of gauge 26, 24, 22, 20 , and 18 less than $454 \mathrm{~kg}$ (1000 pounds) is about $\$ 5.79 / \mathrm{kg}(\$ 2.63 / \mathrm{lb})$ [2]. Table 3 shows the material cost saving per unit length for an $813 \mathrm{~mm} \times 406 \mathrm{~mm}(32$ " $\times 16$ ") duct with $R=2$.

2) Stress and Structure Consideration

\section{- Stress Concentration}

As we know, a geometric stress concentration will occur whenever there is a discontinuity or non-uniformity on the surface of an object. The perimeter of a rectangular duct has sharp turns while the perimeter of a round duct continues smoothly. The round duct with less stress concentration, therefore, will have a longer life time in operation.

- Structure Stability

It is also known when a pressurized air or gas stream is flowing in the ductwork, the duct will stand for internal force. The round duct has the stronger structure stability than the rectangular duct as per the internal stress analysis. Therefore, strength components used in the rectangular duct may not be necessary in the round duct, such as anger-steels in section side and flow direction. It will reduce the duct material and labor in fabrication. As a result, the material and fabrication cost is reduced.

3) Other Savings

- If insulation needed, the ducts are typically lined with faced fiber glass blankets (duct liner) or wrapped externally with $25 \mathrm{~mm}$ by $50 \mathrm{~mm}$ (1" by 2") layer fiber glass blankets (duct wrap). Since the perimeter of the round duct is less than that of the rectangular duct, the insulation materials will be reduced. 
Table 3. Material cost savings per unit length.

\begin{tabular}{cccc}
\hline Gauge & Thickness mm (inch) & Mass $\mathrm{kg} / \mathrm{m}^{2}\left(\mathrm{lbs} / \mathrm{ft}^{2}\right)$ & Cost Savings $\$ / \mathrm{m}(\$ / \mathrm{ft})$ \\
\hline 26 & $0.56(0.022)$ & $4.423(0.906)$ & $12.50(3.81)$ \\
24 & $0.71(0.028)$ & $5.644(1.156)$ & $15.98(4.87)$ \\
22 & $0.86(0.034)$ & $6.864(1.406)$ & $19.42(5.92)$ \\
20 & $1.02(0.040)$ & $8.085(1.656)$ & $22.87(6.97)$ \\
18 & $1.32(0.052)$ & $10.526(2.156)$ & $29.76(9.07)$ \\
\hline
\end{tabular}

- Delivery cost is based on the material mass, which is about $\$ 0.33 / \mathrm{kg}(\$ 0.15 / \mathrm{lb})$ [2] typically. Since duct mass is dropped due tothe duct material reduction, the delivery cost will be reduced consequently.

Example:

A $305 \mathrm{~m}$ (1000 ft) long ductsystem will supply $102 \mathrm{~m}^{3} /$ minute (3600 CFM) air. In design, the friction of per $305 \mathrm{~m}(100 \mathrm{ft})$ duct is $2 \mathrm{~mm}(0.08$ ") W.C., and a diameter D = $610 \mathrm{~mm}$ (24") round duct is selected [3]. With the equal friction, an $813 \mathrm{~mm} \times 406 \mathrm{~mm}$ $(32 " \times 16 ")$ rectangular duct can be used alternatively. Therefore,

The perimeter of the round duct is

$\mathrm{L}=\pi \mathrm{D}=1.92 \mathrm{~m}(6.3 \mathrm{ft})$

The perimeter of the rectangular duct will be

$\mathrm{L}=813 \mathrm{~mm} \times 406 \mathrm{~mm}\left(32 " \times 16^{\prime \prime}\right)=2.4 \mathrm{~m}(8.0 \mathrm{ft})$

For the $305 \mathrm{~m}$ (1000 ft) long 22 gauge duct system, the total duct material saving will be

Material saving per unit square area $=305 \mathrm{~m} \times(2.4 \mathrm{~m}-1.92 \mathrm{~m})=146.4 \mathrm{~m}^{2}\left(1576 \mathrm{ft}^{2}\right)$

Referring to Table 3, the total material cost saving for gauge 22 will be

Material cost saving $=305 \mathrm{~m} \times 19.42 \$ / \mathrm{m}=5923 \$$

Table 4 shows the material cost savings for a $305 \mathrm{~m}$ (1000 ft) long duct system with gauge $26,24,22,20$, and 18 in the same design conditions, respectively. It can be seen for a long duct system, the material cost saving is significant!

\section{Material Cost Saving in LCC Analysis}

The material cost saving can be applied with other saving in life cycle cost (LCC) analysis to have the total cost savings of a duct system during the assigned system lift time. The other savings, for example, $\mathrm{O} \& \mathrm{M}$ cost and salvage or MV cost. The material cost saving need to be converted to PW, AW, and FW in the LCC analysis [4]. The PW, AW and FW of material cost saving are calculated by

$$
\begin{gathered}
\mathrm{PW}=\text { Material Cost Saving(S) } \\
\text { AW = Material Cost Saving }(\$)(A / \mathrm{P}, i \%, n)=\frac{i(1+i)^{n}}{(1+i)^{n}-1} \\
\text { FW = Material Cost Saving }(\$)(F / \mathrm{P}, i \%, n)=(1+i)^{n}
\end{gathered}
$$

As an illustration, the PW, AW, and FW of the material cost saving of gauge 22 from the above example in Section 2 with the following assignments are shown in Table 5. 
Table 4. Material cost savings.

\begin{tabular}{ccc}
\hline Gauge & Saving per Unit Length $\$ / \mathrm{m}(\$ / \mathrm{ft})$ & Material Cost Saving \$ \\
\hline 26 & $12.50(3.81)$ & 3810 \\
24 & $15.98(4.87)$ & 4870 \\
22 & $19.42(5.92)$ & 5920 \\
20 & $22.87(6.97)$ & 6970 \\
18 & $29.76(9.07)$ & 9070 \\
\hline
\end{tabular}

Table 5. Savings with variation of $i$ and $n$.

\begin{tabular}{cccccccc}
\hline & & \multicolumn{3}{c}{ AWb $[\$]$} \\
\cline { 3 - 7 } & PW $[\$]$ & $6 \%$ & $8 \%$ & $10 \%$ & $6 \%$ & $8 \%$ & $10 \%$ \\
\hline 15 & 5920 & 610 & 691 & 779 & 14,188 & 18,779 & 24,699 \\
20 & 5920 & 516 & 603 & 696 & 18,986 & 27,593 & 39,827 \\
25 & 5920 & 463 & 555 & 652 & 25,408 & 40,543 & 64,141 \\
30 & 5920 & 430 & 526 & 628 & 34,002 & 59,571 & 103,300 \\
\hline
\end{tabular}

Interest Rate $(i)=6 \%, 8 \%$, and $10 \%$, respectively

Life Time $(n)=15,20,25$, and 30 years, respectively

\section{Conclusion}

The cross-sectional shape of a gas and air duct system applied for equipment connection, HVAC, medium transport, and exhaust can be selected in either round or rectangle. From geometric calculation and stress analysis, however, the round duct has the less perimeter and stronger structure of the flow. As a result, the duct material can be saved with the equal flow friction and other benefits, such as the ductwork life time can be obtained in the same working condition by using the round duct comparing to the rectangular duct. The calculation from the example illustrates for a large duct system, the material and material cost saving are significant.

- It is concluded that the round cross-section shape is optimal comparing to the square shape and rectangle shape for the gas and air duct system.

- It is suggested the round duct in the gas and air ductwork should be applied as long as the field conditions are allowed.

\section{References}

[1] Lindeburg, M.R. (2006) Mechanical Engineering Reference Manual, Professional Publications, Inc. 12th Edition, Belmont, Chap. 20, 20-14.

[2] Thompson, J.A. (2014) National Plumbing \& HVAC Estimator. Craftsman Book Company, New York City.

[3] (2015) Testing, Adjusting and Balancing Bureau (TABB). www.tabbcertificate.org

[4] Sullivan, W. (2012) Engineering Economy, Fifteenth Edition, Prentice Hall. www.pearsonhighered.com 


\section{Abbreviations}

AW: annual worth

CFM: cubic feet per minute

D: round duct diameter

FW: future worth

HVAC: heating, ventilation, and air conditioning

L: perimeter of duct cross-section

LCC: life cycle cost

MV: market value

PW: present worth

$R$ : aspect ratio

a: short-side length of rectangular duct

$b$ : long-side length of rectangular duct

$\mathrm{ft}$ : foot, feet

$\mathrm{i}$ :annual interest rate

k.perimeter ratio

lb: pound

$\mathrm{n}$ : life time period

\$: US dollar

Conversions

\begin{tabular}{ccc}
\hline & U.S. Customary & SI \\
\hline \multirow{2}{*}{ Length } & 1 inch & $25.4 \mathrm{~mm}$ \\
& 1 foot & $0.3048 \mathrm{~m}$ \\
Mass & 1 pound & $4.5359 \mathrm{~kg}$ \\
\hline
\end{tabular}

Submit or recommend next manuscript to SCIRP and we will provide best service for you:

Accepting pre-submission inquiries through Email, Facebook, LinkedIn, Twitter, etc.

A wide selection of journals (inclusive of 9 subjects, more than 200 journals)

Providing 24-hour high-quality service

User-friendly online submission system

Fair and swift peer-review system

Efficient typesetting and proofreading procedure

Display of the result of downloads and visits, as well as the number of cited articles

Maximum dissemination of your research work

Submit your manuscript at: http://papersubmission.scirp.org/

Or contactwjet@scirp.org 